九州大学学術情報リポジトリ

Kyushu University Institutional Repository

\title{
Preparation of Liposomal Microcapsules by Proliposome Method with Soybean Lecithin
}

Ishikawa, Hiroya

Laboratory of Food Analysis, Division of Food Biotechnology, Department of Bioscience and Biotechnology, Faculty of Agriculture, Kyushu University

Shimoda, Yoshihiro

Laboratory of Food Analysis, Division of Food Biotechnology, Department of Bioscience and Biotechnology, Faculty of Agriculture, Kyushu University

Matsumoro, Kiyoshi

Laboratory of Food Analysis, Division of Food Biotechnology, Department of Bioscience and Biotechnology, Faculty of Agriculture, Kyushu University

https://doi.org/10.5109/4572

出版情報: 九州大学大学院農学研究院紀要. 49 (1)，pp.119-127，2004-02-01. Faculty of Agriculture, Kyushu University

バージョン：

権利関係 : 


\title{
Preparation of Liposomal Microcapsules by Proliposome Method with Soybean Lecithin
}

\author{
Hiroya ISHIKAWA*, Yoshihiro SHIMODA, \\ and Kiyoshi MATSUMOTO
}

\author{
Laboratory of Food Analysis, Division of Food Biotechnology, Department \\ of Bioscience and Biotechnology, Faculty of Agriculture, \\ Kyushu University, Fukuoka 812-8581, Japan \\ (Received October 30, 2003 and accepted November 14, 2003)
}

\begin{abstract}
Liposomal encapsulation was carried out with soybean and egg yolk lecithins. Bovine serum albumin (BSA) was encapsulated by proliposome and dehydration-rehydration (DR) method. Highest encapsulation efficiency (41.9\%) was achieved by proliposome method with soybean lecithin. Encapsulation efficiency of BSA by proliposome method increased to $61.5 \%$ by the addition of trehalose. Stability of the proliposome-capsules was determined under the $\mathrm{pH}$ of 3,5 , and 7. Degradation of the capsules was observed at $\mathrm{pH} 3$ and BSA was released from the capsules. To stabilize proliposome-capsules under acidic conditions, ethanol-soluble fraction of soybean lecithin was used to prepare the capsules. The capsules showed high stability at pH 3 and encapsulated BSA was retained $74.5 \%$ after incubation at $37^{\circ} \mathrm{C}$ for $2 \mathrm{~h}$. In addition, the proliposome-capsules with ethanol-soluble fraction of soybean lecithin exhibited high resistance against the simulated gastric solution $(\mathrm{pH} 1.2)$, while the capsules were readily degraded by Hofmann bile salt solution. These results suggest that the proliposome-capsules would be useful for targeted delivery of functional food ingredients acted in the intestinal tract.
\end{abstract}

\section{INTRODUCTION}

Microencapsulation technique is employed in various areas such as the pharmaceutical, oil, and food industries (Balassa and Fanger, 1971; Lasic, 1998). Through this procedure, liquid droplets, solid particles, or gaseous materials with physiological activity are packaged into the shells that protect and control their release at controlled rates under desired conditions. In food industry, microencapsulation technique has been applied to stabilize the core material, to control the release of the core material, and to separate reactive or incompatible components of formulation (Dziezak, 1988).

Liposomes, a type of microcapsule, enclose liquid compartments with their multilamellar structure consisting of lipid bilayers. Liposomes are useful in various fields because of the small size, high encapsulation efficiency, and so on. Phospholipids are commonly used to prepare liposomes. Egg yolk lecithin has been used in a number of studies because phosphatidilcholine, a major component of egg yolk lecithin, forms liposomes efficiently. Various methods to prepare liposomes have been reported. Dehydration-rehydration (DR) method (Kirby and Gregoriadis, 1984), Reverse-phase evaporation vesicle (REV) method (Szoka and Papahadjopoulos, 1978), and Proliposome method (Perrett et al., 1991) were used because of their high encapsulation efficiency for water-soluble materials.

\footnotetext{
* Corresponding author (E-mail: ishikawa@agr.kyushu-u.ac.jp)
} 
In food industry, there are many restrictions to prepare liposomes. Organic solvents, such as chloroform, diethyl ether, or methanol, cannot be used for the liposome preparation because organic solvents have a possible risk to human health. In addition, egg yolk lecithin is too expensive for large-scale production of microcapsules in food applications. In this study, we tried to prepare liposomal microcapsules with ethanol and soybean lecithin. Encapsulation behavior of bovine serum albumin (BSA), a model compound, was investigated by using proliposome methods. Stability of the capsules was determined under various $\mathrm{pH}$. In addition, resistance of the capsules against simulated gastric juice and degradation of the capsules by bile acids were investigated for targeted delivery of functional food ingredients acted in the intestinal tract.

\section{MATERIALS AND METHODS}

\section{Materials}

Soybean lecithin, egg yolk lecithin, bovine serum albumin (BSA), phosphatidylcholine (PC), phosphatidylethanolamine (PE), trehalose were purchased from Nacalai Tesque Co., Tokyo, Japan. Phosphatidylinositol (PI) was purchased from Sigma Chemical Co., Tokyo, Japan. Bile salts (glycocholic acid, glycochenodeoxycholic acid, glycodeoxycholic acid, taurocholic acid, taurochenodeoxycholic acid, and taurodeoxycholic acid) were purchased as sodium salts from Sigma Chemical Co. (St. Louis, MO, U. S. A.). All other chemicals were obtained from Nacalai Tesque Co. and were of analytical reagent grade.

\section{Preparation of liposomal microcapsules by proliposome method}

Proliposome-microcapsules were prepared according to the method described by Perrett et al. (1991) and Rengel et al. (2002). Lecithin (250 mg) and ethanol (200 $\mu \mathrm{l})$ was stirred and heated to $60^{\circ} \mathrm{C}$ for $5 \mathrm{~min}$. After cooling to room temperature, $500 \mu \mathrm{l}$ of aqueous solution containing BSA ( $25 \mathrm{mg}$ ) was added. The proliposome mixture was converted to a liposome suspension by dropwise-addition of $20 \mathrm{ml}$ of $10 \mathrm{mM}$ phosphate buffer ( $\mathrm{pH} \mathrm{7.0)}$ under the controlled drop rate $(1.5 \mathrm{ml} / \mathrm{min})$ and stirred for $30 \mathrm{~min}$. The prepared liposome suspension was left to hydrate at $2{ }^{\circ} \mathrm{C}$. Proliposome-capsules were obtained by ultracentrifugation at $80000 \times \mathrm{g}$ for $45 \mathrm{~min}$ at $4^{\circ} \mathrm{C}$. Unencapsulated BSA in supernatant of liposome suspension was measured by Bio-Rad protein assay kit using BSA as a standard and encapsulation efficiency of BSA was calculated by following equation:

Encapsulation efficiency (\%)

$=(($ added BSA $(\mathrm{mg})-\mathrm{BSA}$ in supernatant of liposome suspension (mg) $)$ / added BSA $(\mathrm{mg})\} \times 100$

\section{Preparation of liposomal microcapsules by dehydration-rehydration method}

Dehydration-rehydration (DR) microcapsules were prepared according to the method described by Kim et al. (1999) with minor modifications. To $150 \mathrm{ml}$ of ethanol, $250 \mathrm{mg}$ of lecithin (soybean or egg yolk) was dissolved. The ethanol was removed on a rotary evaporator (Tokyo Rikakikai, Japan) under reduced pressure, and then the dried lipid film formed was suspended in $20 \mathrm{ml}$ of deionized water. The suspension was sonicated at $60 \mathrm{~W}$ using a bath type sonicater (SONO CREANER 100A, Kaijo Denki, Japan) for 
$5 \mathrm{~min}$. The suspension was mixed with $10 \mathrm{ml}$ of aqueous solution containing BSA ( $25 \mathrm{mg}$ ) and stirred by vortexing for $5 \mathrm{~min}$. Then, the suspension was lyophilized for $12 \mathrm{~h}$ under vacuum in freeze-dryer (Shimadzu Co., Kyoto, Japan). Deionized water ( $30 \mathrm{ml}$ ) was added to the freeze-dryed preparation and mixed. Dehydration-rehydration liposome-capsules were obtained by ultracentrifugation at $80000 \times \mathrm{g}$ for $45 \mathrm{~min}$ at $4^{\circ} \mathrm{C}$. Unencapsulated BSA in supernatant of liposome suspension was measured by Bio-Rad protein assay kit. Encapsulation efficiency of BSA was calculated in a similar manner as described above.

\section{Preparation of ethanol soluble fraction of soybean lecithin}

Soybean lecithin was dissolved in ethanol and stirred thoroughly. After centrifugation at $3000 \times \mathrm{g}$ for $5 \mathrm{~min}$ at $4^{\circ} \mathrm{C}$, the supernatant was evaporated on a rotary evaporator to remove solvent. After evaporation, $300-400 \mathrm{mg}$ of ethanol-soluble fraction was obtained from $1 \mathrm{~g}$ of soybean lecithin.

\section{pH stability measurement of proliposome-capsules}

Liposomes were incubated in Mcllvaine buffer $\left(\mathrm{pH} \mathrm{3,5}\right.$, and 7) at $37^{\circ} \mathrm{C}$ for $2 \mathrm{~h}$ (liposome concentration: ca. $1.5 \mathrm{mg} \mathrm{lipid} / \mathrm{ml}$ ). After incubation, the suspension was ultracentrifuged at $80000 \times \mathrm{g}$ for $45 \mathrm{~min}$ at $4^{\circ} \mathrm{C}$. Released BSA in supernatant was measured by Bio-Rad protein assay kit using BSA as a standard. The percent retention of BSA was calculated by following equation:

Retention (\%)

$$
\begin{aligned}
= & \{(\text { encapsulated BSA }(\mathrm{mg})-\text { released BSA (mg) / encapsulated BSA (mg) ) }\} \\
& \times 100
\end{aligned}
$$

\section{Stability measurement of proliposome-capsules against simulated gastric solution}

Liposomes were incubated in simulated gastric juice $(\mathrm{pH} 1.2, \mathrm{HCl}$ solution containing $0.2 \% \mathrm{NaCl}$ ) at $37^{\circ} \mathrm{C}$ for $2 \mathrm{~h}$ (liposome concentration: ca. $1.5 \mathrm{mg}$ lipid $/ \mathrm{ml}$ ). After incubation, the suspension was ultracentrifuged at $80000 \times \mathrm{g}$ for $45 \mathrm{~min}$ at $4^{\circ} \mathrm{C}$ and released BSA in supernatant was measured and the percent retention of BSA was calculated as described above.

\section{Degradation of proliposome-capsules with bile salts}

Liposomes were incubated at $37^{\circ} \mathrm{C}$ for $30 \mathrm{~min}$ in $10 \mathrm{mM}$ artificial bile salt solution described by Hofmann (1963). Hofmann bile acid solution, which simulated human intestinal content, was prepared by mixing of the six bile salts at the following ratio (by volume): sodium glycocholate, $30 \%$; sodium glycochenodeoxycholate, $30 \%$; sodium glycodeoxycholate, 15\%; sodium taurocholate, $10 \%$; sodium taurochenodeoxycholate, 10\%; sodium taurodeoxycholate, $5 \%)$. The turbidity at $450 \mathrm{~nm}\left(\mathrm{~T}_{450 \mathrm{~nm}}\right)$ was monitored. The degradation percentage of capsules was calculated by following equation:

$$
\text { Degradation }(\%)=\frac{A-B}{A-C} \times 100
$$

where $\mathrm{A}$ is the turbidity at $0 \mathrm{~min}, \mathrm{~B}$ is the turbidity during the treatment, and $\mathrm{C}$ is the 
turbidity after complete degradation by treating with $10 \mathrm{mM}$ Hofmann bile acid solution at $37^{\circ} \mathrm{C}$ for $60 \mathrm{~min}$.

\section{RESULTS AND DISCUSSION}

\section{Encapsulation of BSA by proliposome and DR methods}

Soybean and egg yolk lecithins were used for liposomal encapsulation of BSA. Encapsulations were done by proliposome and DR methods with ethanol. Encapsulation efficiencies of BSA by these methods were shown in Fig. 1. Highest encapsulation efficiency (41.9\%) was obtained by proliposome method with soybean lecithin. The efficiency was about $20 \%$ higher than that of encapsulation with egg yolk lecithin (by proliposome and DR methods). On the other hand, encapsulation efficiency by DR method with soybean lecithin was only $10.7 \%$. This low efficiency might be resulted from ethanol-insoluble property of phosphatidylinositol, which is one of major phospholipids in soybean lecithin. Phosphatidylinositol would inhibit liposomal encapsulation by preventing a thin film formation in ethanol-system on DR method and cause the decrease in the encapsulation efficiency.

Figure 2 shows the encapsulation efficiency of BSA by proliposome method with various amounts of soybean lecithin. Highest encapsulation efficiency of BSA (25 mg) on proliposome method was obtained by using $250 \mathrm{mg}$ of lecithin.

Crowe et al. (1986) reported that trehalose would stabilize liposomal membrane by the formation of hydrogen bonds with phosphate groups of phospholipids. Kim et al. (1999) indicated that the amounts of $\beta$-galactosidase entrapped in DR-liposomes increased by the addition of trehalose. In the present study, we investigated the effect of
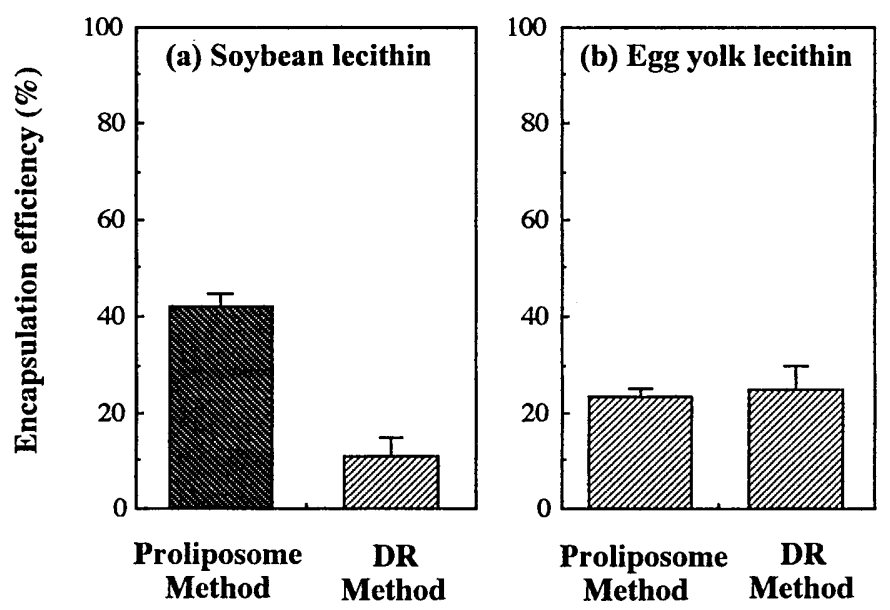

Fig. 1. Encapsulation of BSA with soybean (a) and egg yolk lecithin (b). Encapsulations were done by proliposome and dehydration-rehydration (DR) methods. The capsules were prepared with $250 \mathrm{mg}$ of lecithin and $25 \mathrm{mg}$ of BSA. Results are expressed as mean $\pm \mathrm{SD}(\mathrm{n}=3)$. 


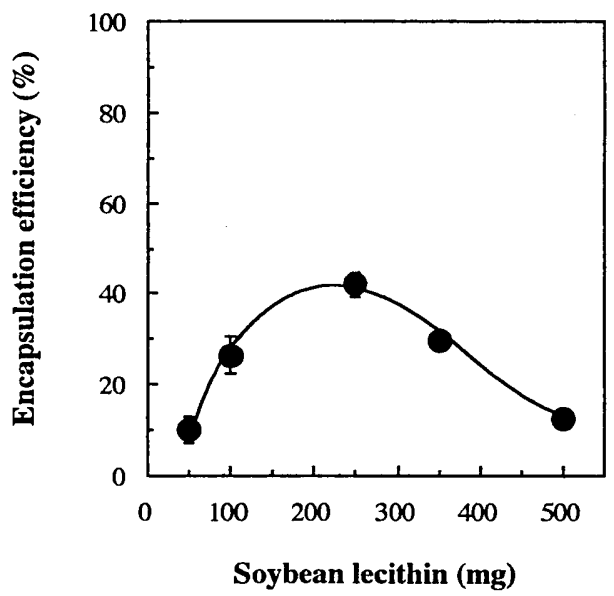

Fig. 2. Encapsulation efficiency by proliposome method with soybean lecithin. The capsules were prepared with $50-500 \mathrm{mg}$ of lecithin and $25 \mathrm{mg}$ of BSA. Each point represents the mean $\pm S D(n=3)$.

trehalose on encapsulation by proliposome method. Encapsulation efficiency of BSA by proliposome method with trehalose was shown in Fig. 3. Encapsulation efficiency by proliposome method increased with increasing the amounts of trehalose. By addition of trehalose $(1 \mathrm{~g} / 250 \mathrm{mg}$ lecithin), $61.5 \%$ of the efficiency was achieved. The result suggests that trehalose would stabilize proliposome-capsules and result in high encapsulation efficiency of BSA.

The $\mathrm{pH}$ stability of proliposome-capsules prepared with soybean lecithin and trehalose was examined (Fig. 4). The capsules were incubated in Mcllvaine buffer at $\mathrm{pH} 3$, 5 , and 7. Incubation temperature and time were set at $37^{\circ} \mathrm{C}$ and $2 \mathrm{~h}$, respectively. High stabilities of proliposome-capsules were observed at $\mathrm{pH} 5$ and 7 . BSA was retained over $90 \%$ after the incubation for $2 \mathrm{~h}$. On the other hand, BSA was easily released from the capsules at $\mathrm{pH} 3$. BSA was retained only $12.6 \%$ after the incubation.

\section{Effect of phospholipids on encapsulation by proliposome method}

The effect of the phospholipids on encapsulation efficiency of BSA was investigated (Fig. 5). Phosphatidylcholine, phosphatidylethanolamine, and phosphatidylinositol were used to prepare proliposome-capsules with soybean lecithin. Encapsulation efficiency of BSA increased with increasing the amounts of PC. The addition of PE exhibited little effect on the encapsulation efficiency. A considerable decrease in the efficiency was observed by addition of PI. Encapsulation efficiency by using $250 \mathrm{mg}$ of PI was only $5.1 \%$. The result suggests that PI would destabilize proliposome-capsules and result in the decrease in the encapsulation efficiency. 


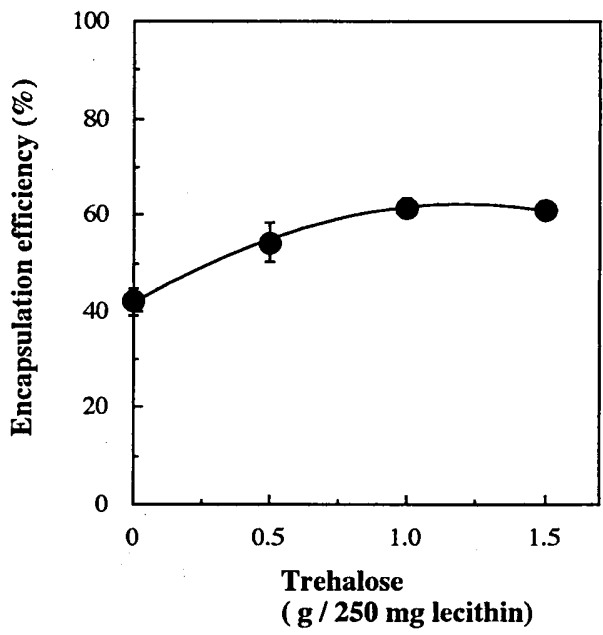

Fig. 3. Effect of trehalose on encapsulation efficiency of BSA by proliposome method. The capsules were prepared with $250 \mathrm{mg}$ of lecithin and $25 \mathrm{mg}$ of BSA. Each point represents the mean $\pm \operatorname{SD}(n=3)$.

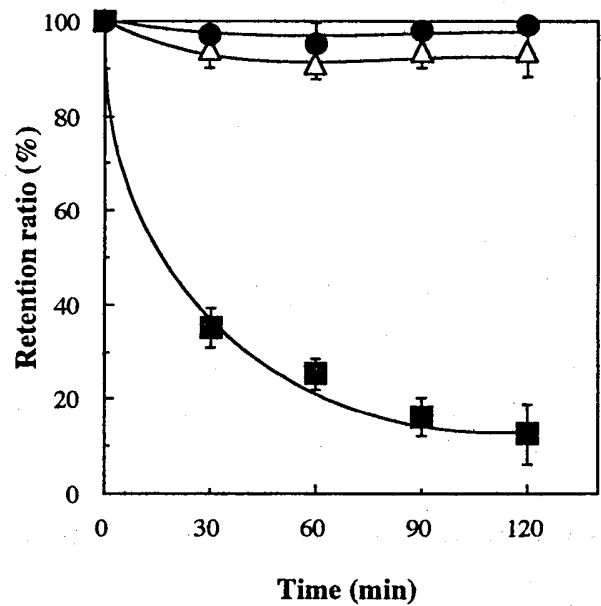

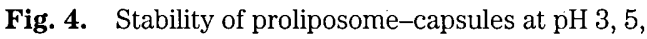
and 7. The capsules were prepared with $250 \mathrm{mg}$ of lecithin and $25 \mathrm{mg}$ of BSA, and incubated in McIlvaine buffer at $37^{\circ} \mathrm{C}$ for 2h. Symbols indicate: $\mathbf{\square}, \mathrm{pH} 3 ; \triangle, \mathrm{pH} 5$; , $\mathrm{pH}$ 7. Each point represents the mean \pm $\operatorname{SD}(n=3)$. 


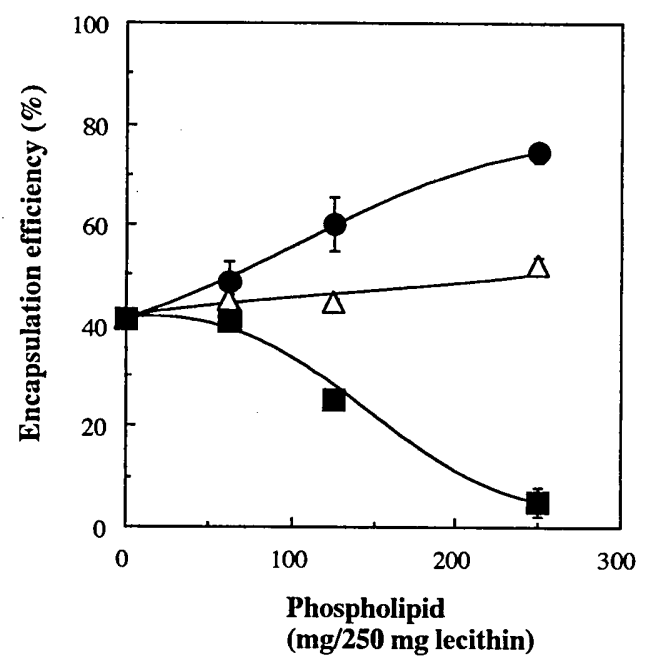

Fig. 5. Effect of the phospholipids on encapsulation efficiency of BSA by proliposome method. Phosphatidylcholine (PC), phosphatidylethanolamine (PE), phosphatidylinositol (PI) were used for the encapsulation. The capsules were prepared with $0-250 \mathrm{mg}$ of each phospholipid, $250 \mathrm{mg}$ of soybean lecithin, and $25 \mathrm{mg}$ of BSA. Symbols indicate:, $\mathrm{PC} ; \triangle, \mathrm{PE} ; \mathbf{D}, \mathrm{PI}$. Each point represents the mean $\pm S D(n=3)$.

\section{Encapsulation of BSA by proliposome method with ethanol soluble fraction of soybean lecithin}

As described above, PI would destabilize proliposome-capsules and cause the decrease in encapsulation efficiency. Thus, we prepared proliposome-capsules with ethanol-soluble fraction, which was free from PI, of soybean lecithin. As a result, encapsulation efficiency of BSA increased to $69.0 \%$ by using ethanol-soluble fraction of soybean lecithin (data not shown).

The $\mathrm{pH}$ stability of proliposome-capsules with ethanol-soluble fraction of soybean lecithin was investigated. The retention of BSA in the capsules under acidic condition was shown in Fig. 6 . The capsules were incubated at $\mathrm{pH} 3$ and $37^{\circ} \mathrm{C}$ for $2 \mathrm{~h}$. Proliposome-capsules with ethanol-soluble fraction exhibited higher stability than that of the capsules with whole soybean lecithin. BSA was retained $74.5 \%$ in proliposome-capsules after the incubation.

To apply proliposome-capsules for targeted delivery of functional food ingredients acted in the intestinal tract, the resistance of the capsules against gastric environment was investigated by monitoring the release of BSA from the capsules. Retention of BSA in proliposome-capsules under simulated gastric juice $(\mathrm{pH} \mathrm{1.2)} \mathrm{was} \mathrm{shown} \mathrm{in} \mathrm{Fig.} 7$. Proliposome-capsules were prepared with ethanol fraction of soybean lecithin and whole soybean lecithin. Proliposome-capsules with whole soybean lecithin were rapidly degrad- 


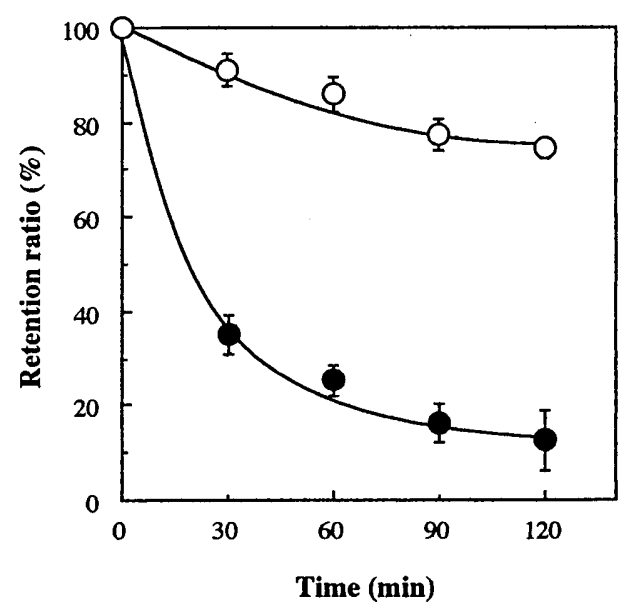

Fig. 6. Stability of proliposome-capsules under acidic condition. The capsules were prepared with ethanol fraction of soybean lecithin and whole soybean lecithin, and incubated at $\mathrm{pH} 3$ and $37^{\circ} \mathrm{C}$ for $2 \mathrm{~h}$. Symbols indicate: $\bigcirc$, ethanol soluble fraction; , whole soybean lecithin. Each point represents the mean $\pm \operatorname{SD}(n=3)$.

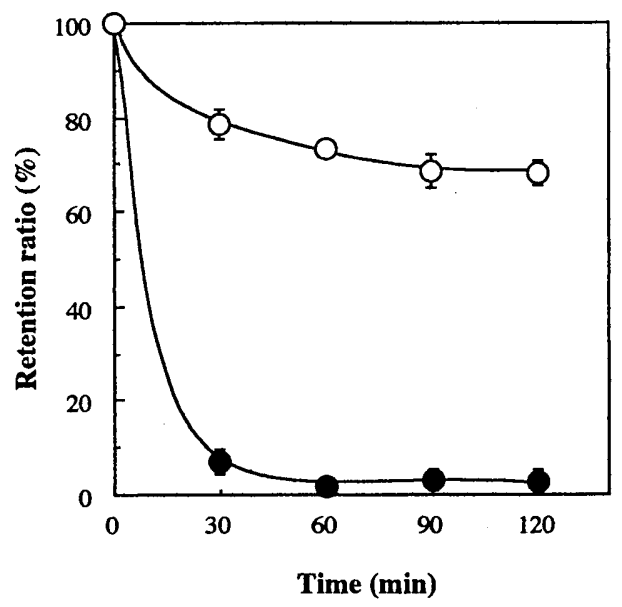

Fig. 7. Resistance of proliposome-capsules against simulated gastric juice $(\mathrm{pH} 1.2)$ at $37^{\circ} \mathrm{C}$. The capsules were prepared with ethanol soluble fraction of soybean lecithin and whole soybean lecithin. Symbols indicate: $\bigcirc$, ethanol soluble fraction; $\mathbf{O}$, whole soybean lecithin. Each point represents the mean $\pm S D(n=3)$. 
ed and BSA was released from the capsules. The percent retention of BSA was only $2.6 \%$ after $2 \mathrm{~h}$. On the other hand, proliposome-capsules with ethanol fraction were more stable under simulated gastric juice. BSA was retained $68.0 \%$ even after $2 \mathrm{~h}$-incubation. In addition, we examined the degradation of proliposome-capsules with $10 \mathrm{mM}$ Hoffmann bile salt solution by turbidity measurement at $450 \mathrm{~nm}$. Proliposome-capsules with ethanol fraction of soybean lecithin were readily degraded by the bile salt solution and $94.6 \%$ of BSA was released from the capsules within 5 min (data not shown). These results suggest that proliposome-capsules would pass through stomach with retaining functional food ingredients, and then, release them in the intestinal tract where the ingredients exhibit their activity.

\section{REFERENCES}

Balassa L. L., and G.O. Fanger 1971 Microencapsulation in the food industry. CRC Crit Rev Food Tech., 7 (3): 245-261

Crowe L. M., C. Womersley, J. H. Crow, D. Reid, L. Appel, and A. Rudolph 1986 Prevention of fusion and leakage in freeze-dried liposomes by carbohydrates. Biochim et Biophys Acta, 861: 131-140

Dziezak J. D. 1988 Microencapsulation und encapsulated ingredients. Food Technol., 42: 136-151

Hofmann A. F. 1963 The function of bile salts in fat absorption. Biochem. J., 89:57-68

Kim C. K., H. S. Chung, M. K. Lee, L. N. Choi, and M. H. Kim 1999 Development of dried liposomes containing b-galactosidase for the digetion of lactose in milk. Int. J. Pharmaceu., 183: 185-193

Kirby C., and G. Gregoriadis 1984 Dehydration-rehydration vesicles(DRV): a new method for high yield drug entrapment in liposomes. Bio. Tech., 2: 979-984

Lasic D. D. 1998 Novel applications of liposomes. Tibtech., 16 (7): 307-321

Perrett S., M. Golding, and W. P. Williams 1991 A simple method for the preparation of liposomes for pharmaceutical applications: characterization of liposomes. J. Pharm., Pharmacol., 43: 154-161

Rengel R. G., K. Barisic, Z. Pavelic, T. Z. Grubisic, I. Cepelak, and J. Filipovic-Grcic 2002 High efficiency entrapment of superoxide dismutase into mucoadhesive chitosan-caoted liposome. Euro. J. Pharmaceu. Sci, 15: 441-448

Szoka F. Jr., and D. Papahadjopoulos. 1978 Procedure for Preparation of liposomes with large internal aqueous space and high capture by reverse-phase evaporation. Proc. Natl. Acad. Sci., USA 75: (9) 4194-4198 